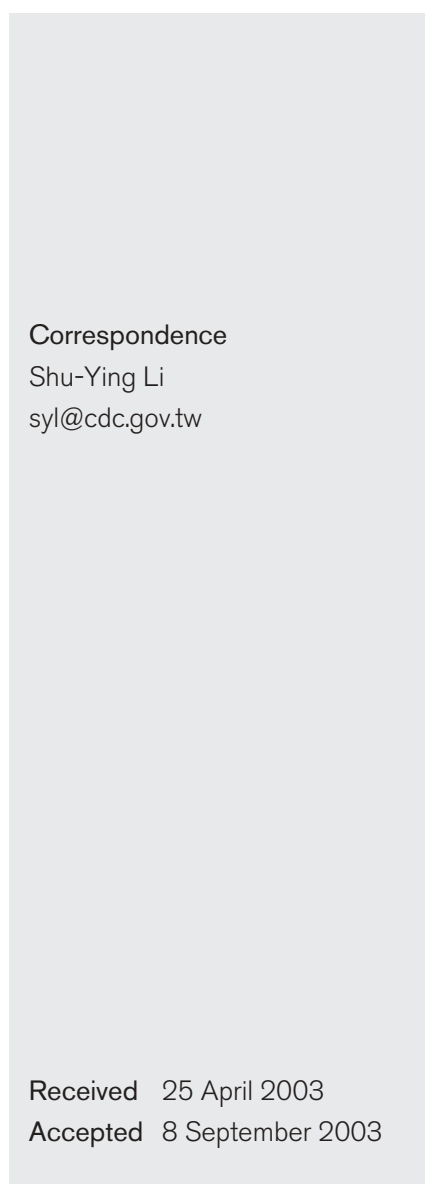

\title{
Species identification of medically important fungi by use of real-time LightCycler PCR
}

\author{
Min-Chih Hsu, ${ }_{1}^{1}$ Kuo-Wei Chen, ${ }^{1}$ Hsiu-Jung Lo, ${ }^{2}$ Yee-Chun Chen, ${ }^{3}$ \\ Mei-Hui Liao, ${ }^{1}$ Yu-Hui Lin ${ }^{1}$ and Shu-Ying Li ${ }^{1}$ \\ ${ }^{1}$ Laboratory for Mycopathogen, Chlamydia and Mycoplasma, Division of Laboratory Research and \\ Development, Center for Disease Control, Taipei, Taiwan \\ ${ }^{2}$ Division of Clinical Research, National Health Research Institutes, Taipei, Taiwan \\ ${ }^{3}$ Department of Internal Medicine, National Taiwan University Hospital, Taipei, Taiwan
}

\begin{abstract}
Invasive fungal infection has become a major cause of morbidity and mortality in immunocompromised patients. Rapid identification of pathogenic fungi to species level is critical for disease treatment. A real-time LightCycler assay aiming at rapid detection and species identification of pathogenic fungi from clinical isolates was developed. Template DNAs of different species were amplified and detected in real time by employing SYBR Green fluorescent dye. The target sequences for species-level detection were located between the $18 S$ and $28 S$ rDNA. Seven fungal species encountered frequently in the clinical setting, Candida albicans, Candida glabrata, Candida krusei, Candida parapsilosis, Candida tropicalis, Candida guilliermondii and Cryptococcus neoformans, could be discriminated by species-specific primers and confirmed by melting-curve analyses. The range of linearity was from $1 \mathrm{ng}$ to $1 \mathrm{pg}\left(\mu \mathrm{l}^{-1}\right.$ water) and the sensitivity was $1 \mathrm{pg}$ fungal DNA $\mu \mathrm{I}^{-1}$. Identification by this real-time PCR method matched biochemical identification for all 58 clinical strains. Therefore, the method is simple, rapid and sensitive enough for detection and identification of several fungal species.
\end{abstract}

\section{INTRODUCTION}

Invasive fungal infections have become major causes of morbidity and mortality among immunocompromised patients (Dasbach et al., 2000; Ellis et al., 2001), such as some neutropenic patients with haematological malignancies and recipients of allogenic bone marrow transplants (Denning, 1998) as well as individuals with AIDS (Mitchell \& Perfect, 1995). Candida species are now the fourth most frequent cause of nosocomial blood-stream infections in critically ill patients in the United States. At a teaching hospital in Taiwan, yeast infection was identified as the leading cause of nosocomial infection (Chen et al., 1997). The increasing prevalence of yeast infections highlights the need for simple and rapid methods to identify clinically important fungi in a microbiological laboratory.

Each Candida species has a different degree of susceptibility to common antifungal agents. For instance, Candida krusei is innately resistant and Candida glabrata, Candida guilliermondii and Candida dubliniensis are less susceptible to fluconazole than other Candida species (Orozco et al., 1998; Piemonte et al., 1996). Emergence of secondary resistance in Candida lusitaniae to amphotericin B has also been observed and monitored closely (Pfaller et al., 2003). Current recommendations suggest that invasive fungal in- fections, such as candidiasis and aspergillosis, should be treated empirically, because the current diagnoses are difficult and time-consuming (Rex et al., 2000; Stevens et al., 2000). However, there is great concern that such practice would result in the emergence of resistant fungal pathogens.

As more and more alternative antifungal agents with various spectra of activities are developed and become available, treatment according to accurate diagnosis has become even more important. Therefore, rapid species identification will be more critical for effective disease therapy and control (Polak, 2003). Conventional diagnostic tests, such as blood culture and biochemical tests, which lack sufficient sensitivity and specificity for early diagnosis of invasive fungal infections, may often require 2 or more days and may be inaccurate (Espinel-Ingroff et al., 1998; Goodwin et al., 1992; Hazen, 1995). Serological tests have certain limitations, e.g. antibody response may be lacking or varied, since the patients most at risk of fungal infections are often immunosuppressed. As for antigen tests, there are no widely accepted Candida antigen tests and most cannot differentiate among Candida species. Other tests, such as those for cryptococcal, aspergillus and histoplasmal antigen, are often hampered by low serum antigen concentrations (Morrison \& Lindsley, 2002; Yeo \& Wong, 2002). 
Therefore, diagnostic assays based on in vitro amplification and detection of fungal DNA have been developed, among which PCR methods are particularly promising because of their high specificity and sensitivity. A number of studies have described restriction fragment length polymorphism, PCR amplification and hybridization with species-specific probes, amplicon size differences (Chen et al., 2001; Fujita et al., 2001; Henry et al., 2000) or other methods to identify unique DNA sequences (Hopfer et al., 1993; Kappe et al., 1998; Martin et al., 2000; Turenne et al., 1999). Although these published PCR methods are quite useful for identification of fungal species, they still require a minimum of several hours for DNA amplification and visualization. More recently, real-time PCR techniques have been developed for the detection of fungal pathogens such as Candida species, Cryptococcus neoformans and Aspergillus species. All these assays demonstrate sensitivities better or at least comparable to previously described PCR methods. Real- time PCR assays dramatically decrease the risk of falsepositive results, because the PCR and detection systems are coupled and conducted in a closed system and no laborious post-PCR analyses are required. Various real-time PCR platforms have been developed. The signal to be analysed can be generated by double-stranded DNA-specific dyes, such as SYBR Green, or by sequence-specific fluorescence energy transfer probes. A couple of exonuclease-based TaqMan PCR assays, capable of rapid identification and speciation of six Candida species (Guiver et al., 2001) or Aspergillus fumigatus (Costa et al., 2002; Kami et al., 2001), have been described. DNA detection methods for Candida albicans, A. fumigatus and Cryptococcus neoformans using the LightCycler have also been reported (Bialek et al., 2002; Loeffler et al., 2000; Spiess et al., 2003). White et al. (2003) described real-time and high-sensitivity detection of seven Candida species using the LightCycler system; however, they were not able to speciate them.

Table 1. Clinical and reference strains used in this study

\begin{tabular}{|c|c|c|c|}
\hline Strain & Source of isolation & Strain & Source of isolation \\
\hline Candida albicans & & Candida guilliermondii & \\
\hline ATCC 14053 & Reference strain & CDC-F276 & Nail \\
\hline CDC-F062 & Urine & CDC-F317 & Blood \\
\hline CDC-F063 & Blood & Candida krusei & \\
\hline CDC-F064 & Urine & ATCC 6258 & Reference strain \\
\hline CDC-F065 & Blood & CDC-F069 & Urine \\
\hline CDC-F066 & Blood & CDC-F072 & Urine \\
\hline CDC-F087 & Urine & CDC-F191 & Blood \\
\hline CDC-F088 & Sputum & CDC-F214 & Blood \\
\hline CDC-F089 & Sputum & Cryptococcus neoformans & \\
\hline CDC-F090 & Sputum & Duke215 & Reference strain \\
\hline CDC-F091 & Sputum & CDC-F360 & Cerebrospinal fluid \\
\hline CDC-F092 & Wound & Candida parapsilosis & \\
\hline CDC-F094 & Sputum & ATCC 20515 & Reference strain \\
\hline CDC-F095 & Sputum & ATCC 22019 & Reference strain \\
\hline CDC-F099 & Sputum & CDC-F074 & Sputum \\
\hline CDC-F102 & Sputum & CDC-F080 & Wound \\
\hline Candida glabrata & & CDC-F084 & Blood \\
\hline ATCC 2001 & Reference strain & CDC-F107 & Blood \\
\hline CDC-F070 & Urine & CDC-F156 & Wound \\
\hline CDC-F073 & Urine & CDC-F159 & Urine \\
\hline CDC-F075 & Sputum & Candida tropicalis & \\
\hline CDC-F078 & Blood & ATCC 750 & Reference strain \\
\hline CDC-F093 & Urine & CDC-F067 & Sputum \\
\hline CDC-F096 & Sputum & CDC-F068 & Sputum \\
\hline CDC-F097 & Urine & CDC-F076 & Sputum \\
\hline CDC-F098 & Urine & CDC-F079 & Wound tissue \\
\hline Candida guilliermondii & & CDC-F081 & Urine \\
\hline ATCC 20862 & Reference strain & CDC-F082 & Urine \\
\hline CDC-F071 & Sputum & CDC-F083 & Urine \\
\hline CDC-F119 & Skin & CDC-F085 & Sputum \\
\hline CDC-F128 & Sputum & CDC-F086 & Urine \\
\hline CDC-F171 & Tinea & CDC-F085 & Sputum \\
\hline CDC-F261 & Blood & CDC-F086 & Urine \\
\hline
\end{tabular}


In this paper, we describe a simple real-time PCR assay with the LightCycler system employing species-specific primers and SYBR Green fluorescent dye for detection and species identification of fungal strains. This assay offers the advantage that the conventional PCR can be easily adapted to realtime format without the need for complicated probe design. The assay has been shown to be amply specific and sensitive and to facilitate the detection procedure significantly.

\section{METHODS}

Fungal strains. Eight reference strains and 50 clinical strains of Candida albicans $(n=16)$, Candida glabrata $(n=9)$, Candida guilliermondii $(n=8)$, Candida krusei $(n=5)$, Candida parapsilosis $(n=8)$, Candida tropicalis $(n=10)$ and Cryptococcus neoformans $(n=2)$ were used in this study (Table 1). Taiwan Surveillance of Antimicrobial Resistance of Yeasts (Lo et al., 2001) collected clinical strains isolated from different body sites and from 22 hospitals located in different geographical locations in Taiwan from 15 April to 15 June 1999. Identification of fungal strains was done by germ-tube assay followed by VITEK yeast biochemical card and API-32C systems. Fungi were cultured on Sabouraud dextrose agar (SDA) plates for $72 \mathrm{~h}$ at $37^{\circ} \mathrm{C}$.

DNA extraction. DNA was extracted by using the PUREGENE DNA purification kit (Gentra). Briefly, two loops of fungal biomass from a 2to 3-day-old culture on SDA were transferred to a 5-ml sterile tube with parafilm seals and re-suspended in $2 \mathrm{ml}$ PBS containing 10-15 $\mu \mathrm{l}$ lyticase and the mixture was incubated overnight at $37^{\circ} \mathrm{C}$. The samples were centrifuged at $13000 \mathrm{~g}$ for $3 \mathrm{~min}$ and the supernatant was removed. Cell lysis solution $(2 \mathrm{ml})$ was added to the cell pellet and gently pipetted up and down to lyse the cells. Next, $1 \mathrm{ml}$ protein precipitation solution was added to the cell lysate and vortexed vigorously at high speed for $20 \mathrm{~s}$ and then centrifuged at $13000 \mathrm{~g}$ for $10 \mathrm{~min}$. The supernatant was mixed with $100 \%$ isopropanol to precipitate DNA. The DNA was washed with $70 \%$ ethanol, air-dried and dissolved in $50 \mu \mathrm{l}$ DNA hydration solution. DNA concentrations were measured with a spectrophotometer $\left(A_{260}\right)$ and DNA samples were stored at $-80^{\circ} \mathrm{C}$ until used.

LightCycler-based PCR. The LightCycler PCR and detection system (Roche Diagnostics) was used for amplification and quantification. PCR was performed in glass capillaries and cycling was achieved by alternating heated air and air of ambient temperature, which ensures rapid equilibration between the air and the reaction components due to the high surface-to-volume ratio of the capillaries. The locations and sequences of the species-specific primers (CALB, CGL, CPA, CTR, CGU, CKRU and CN) are shown in Fig. 1 and Table 2 (Lindsley et al.,

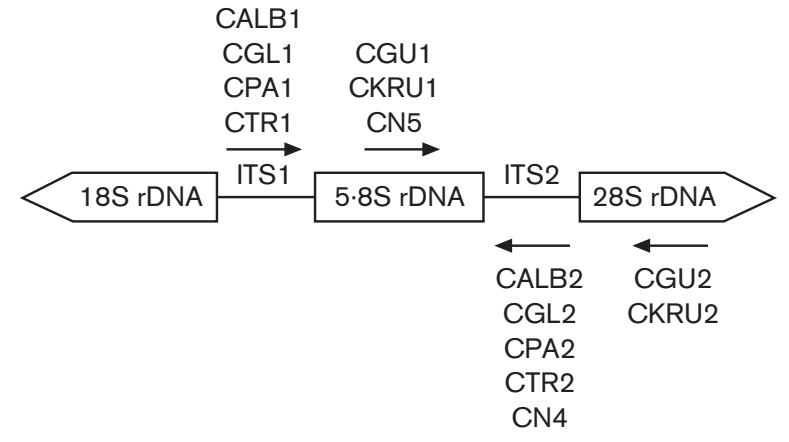

Fig. 1. Specific primer sites for the real-time PCR.
2001; Luo \& Mitchell, 2002). For amplicon detection, the LightCycler FastStart DNA Master SYBR Green kit was used as described by the manufacturer. The PCR mixture $(20 \mu \mathrm{l})$ contained Taq polymerase, $1 \times$ LightCycler reaction buffer, $3 \mathrm{mM}$ magnesium chloride and $0.5 \mu \mathrm{M}$ primers. Template DNA was added at a final concentration of $1 \mathrm{ng}$ per $20 \mu \mathrm{l}$ reaction mixture. Samples were run in parallel by performing 35 cycles of repeated denaturation $\left(5 \mathrm{~s}\right.$ at $\left.95^{\circ} \mathrm{C}\right)$, annealing $\left(5 \mathrm{~s}\right.$ at $58^{\circ} \mathrm{C}$ ) and chain extension $\left(25 \mathrm{~s}\right.$ at $\left.72{ }^{\circ} \mathrm{C}\right)$. This step was followed by a meltingcurve analysis from 60 to $95^{\circ} \mathrm{C}$ and, afterwards, cooling to $40{ }^{\circ} \mathrm{C}$. The PCR was completed within $45 \mathrm{~min}$. The PCR process was then monitored by fluorescence quantification of the DNA-binding dye SYBR Green 1 dye for the detection of double-stranded DNA.

Agarose gel electrophoresis. Gel electrophoresis was conducted in TBE buffer (0.1 M Tris/HCl, 0.09 M boric acid, $1 \mathrm{mM} \mathrm{EDTA,} \mathrm{pH} \mathrm{8.4)} \mathrm{at}$ $100 \mathrm{~V} \mathrm{~cm}^{-1}$ for $50 \mathrm{~min}$ in gels composed of $2.0 \%(\mathrm{w} / \mathrm{v})$ agarose (BioWhittaker) and stained in $0.5 \mu \mathrm{g}$ ethidium bromide $\mathrm{ml}^{-1}$ for $15 \mathrm{~min}$ followed by washing for $15 \mathrm{~min}$ with distilled water.

\section{RESULTS AND DISCUSSION}

The increasing frequency of invasive fungal infections and the high mortality associated with disseminated fungal diseases have underscored the importance of rapid detection of pathogenic fungi. Prompt detection and accurate speciation may help to improve fungal disease management as a whole and lead to more rational use of antifungals. Traditional identification methods based on phenotypic features are often time-consuming and depend largely on the skill and experience of the technician. Therefore, we evaluated the feasibility of LightCycler PCR amplification of the rDNA region followed by melting-curve analysis for identification of clinically important yeasts.

The specificity of LightCycler amplification was tested by annealing the Candida albicans-specific primers CALB1 and CALB2 with DNA extracted from Candida albicans ATCC 14053. The detection limit was about $1 \mathrm{pg} \mu^{-1}$ (Fig. 2). Similar results were observed with DNA of other species, i.e. the specific primers for each fungal species react only with DNA from the homologous fungal species (data not shown).

The range of linearity was tested by amplification of 10 -fold serial dilutions of purified Candida albicans ATCC 14053 DNA with fluorescence plotted against number of cycles. Linearity was achieved over 4 logs of input fungal DNA amount, from $1 \mathrm{ng}$ to $1 \mathrm{pg}^{-1} \mathrm{l}^{-1}$ (Fig. 3).

Compared with bacteraemia or viraemia, fungaemia has much lower pathogen load. Therefore, high-sensitivity detection is pivotal for timely management of fungal diseases. The sensitivity of the assays was evaluated by amplifying DNAs of six Candida species and Cryptococcus neoformans by their respective primers with the LightCycler, and the detection limit of this method was about $1 \mathrm{pg}$ DNA $\mu^{-1}$. Serially diluted samples of reference strains ranging from $1 \mathrm{ng}$ to $1 \mathrm{pg} \mathrm{DNA} \mu \mathrm{l}^{-1}$ showed a single band with the specific primers in all cases (Fig. 4).

In order to determine the utility of the LightCycler speciesspecific amplification method for accurate identification of fungal species, analyses of clinical strains were conducted. 
Table 2. Primers for PCR amplification

Odd-numbered primers are forward primers and even-numbered primers are reverse primers.

\begin{tabular}{|c|c|c|c|}
\hline Primer & Sequence $\left(5^{\prime}-3^{\prime}\right)$ & Amplicon (bp) & $\begin{array}{l}\text { Reference/GenBank } \\
\text { accession no. }\end{array}$ \\
\hline \multicolumn{4}{|c|}{ Candida albicans } \\
\hline CALB1 & TTTATCAACTTGTCACACCAGA & $\sim 273$ & L47111 \\
\hline CALB2 & ATCCCGCCTTACCACTACCG & & L28817 \\
\hline \multicolumn{4}{|c|}{ Candida glabrata } \\
\hline CGL1 & TTATCACACGACTCGACACT & $\sim 423$ & AB032177 \\
\hline CGL2 & CCCACATACTGATATGGCCTACAA & & AF167993 \\
\hline \multicolumn{4}{|c|}{ Candida guilliermondii } \\
\hline CGU1 & GCATCGATGAAGAACGCAGC & $\sim 315$ & AX592669 \\
\hline CGU2 & GTTTGGTTGTTGTAAGGCCGGG & & Elie et al. (1998) \\
\hline \multicolumn{4}{|c|}{ Candida krusei } \\
\hline CKRU1 & GCATCGATGAAGAACGCAGC & $\sim 258$ & AX592669 \\
\hline CKRU2 & AAAAGTCTAGTTCGCTCGGGCC & & Elie et al. (1998) \\
\hline \multicolumn{4}{|c|}{ Candida parapsilosis } \\
\hline CPA1 & GCCAGAGATTAAACTCAACCAA & $\sim 300$ & AF287909 \\
\hline CPA2 & CCTATCCATTAGTTTATACTCCGC & & L47109 \\
\hline \multicolumn{4}{|c|}{ Candida tropicalis } \\
\hline CTR1 & CAATCCTACCGCCAGAGGTTAT & $\sim 357$ & AF287910 \\
\hline CTR2 & TGGCCACTAGCAAAATAAGCGT & & AF268095 \\
\hline \multicolumn{4}{|c|}{ Cryptococcus neoformans } \\
\hline CN5 & GAAGGGCATGCCTGTTTGAGAG & $\sim 136$ & M94516 \\
\hline CN4 & АТСАССТТСССАСТААСАСАТТ & & M94517 \\
\hline
\end{tabular}

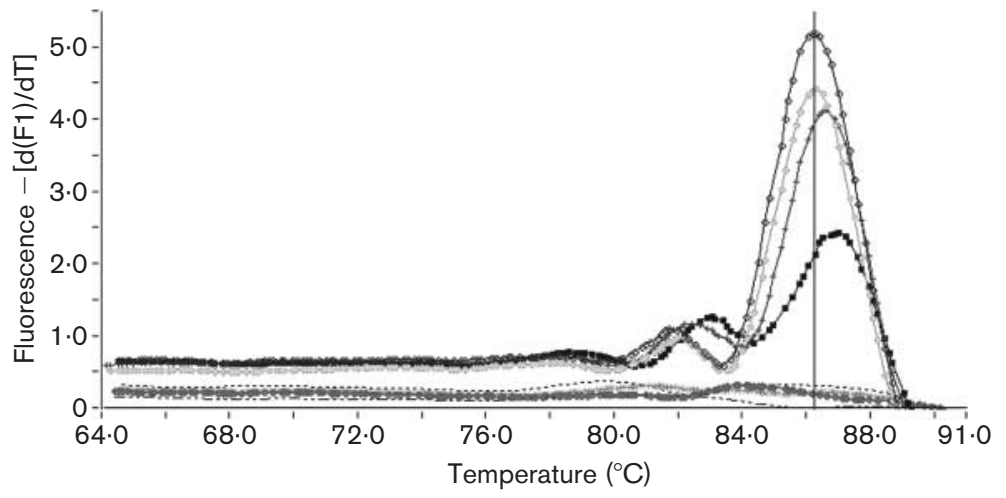

Fig. 2. Sensitivity of the Candida albicans ATCC 14053 DNA-specific primers CALB1 and CALB2. Characteristic dose-dependent melting peaks were observed in the presence of DNA from Candida albicans ATCC $14053[1 \mathrm{ng}(\diamond)$ to $\left.1 \mathrm{pg}(\mathbf{\square}) \mu^{-1}\right]$.

The identification results from our real-time PCR method matched completely with biochemical identification results for all 58 tested samples. Characteristic peak $T_{\mathrm{m}}$ for speciesspecific primers with their respective fungal species were obtained by melting-curve analyses (Table 3 ).

Targets for species-level detection of fungal pathogens include the 18S rDNA, mitochondrial DNA (Yamada et al., 2002), the internal transcribed spacer (ITS) regions and many other genes (Kanbe et al., 2002). rDNA offers distinct advantages over other molecular targets because of greatly increased sensitivity due to the existence of approximately 100 copies per genome. Many Candida species can be differentiated by analysis of fragment length variation in
ITS1 (Chen et al., 2001) or ITS2 (De Baere et al., 2002). The LightCycler system offers another advantage of analysis of the melting temperature of amplicons. The melting temperature of the amplicon is dependent on the $\mathrm{G}+\mathrm{C}$ content, sequence length and compositional variation in the nucleotide bases. Each fungal species has a characteristic $T_{\mathrm{m}}$, which helps further to confirm its identity.

In conclusion, the real-time LightCycler PCR assay combines rapid amplification of DNA with real-time species determination. The routine block cycler PCR protocol can be easily transferred and adapted to the real-time protocol. This method is simple, rapid and sensitive and can therefore streamline the flow of diagnostic laboratory work. 

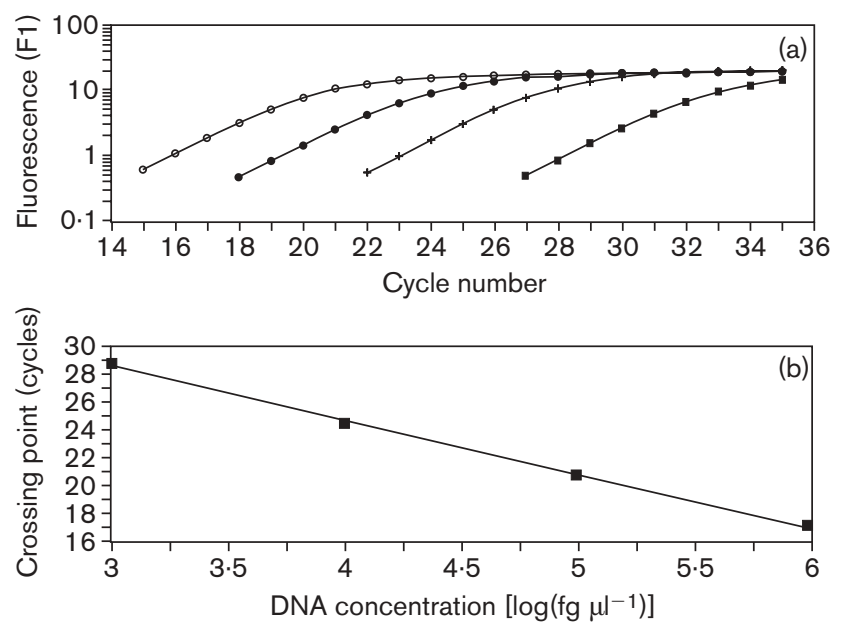

Fig. 3. (a) Quantification of serially diluted Candida albicans ATCC 14053 DNA [ $1 \mathrm{ng}$ to $1 \mathrm{pg} \mathrm{\mu l}^{-1}$ ] with CALB1 and CALB2 primers using the LightCycler software. (b) Log DNA concentration ( $f g \mathrm{l}^{-1}$ ) against fluorescence. Slope (-3.924), y-intercept (40.31), mean squared error $(0 \cdot 100)$ and regression coefficient $(-1.00)$ of the standard curve were calculated.

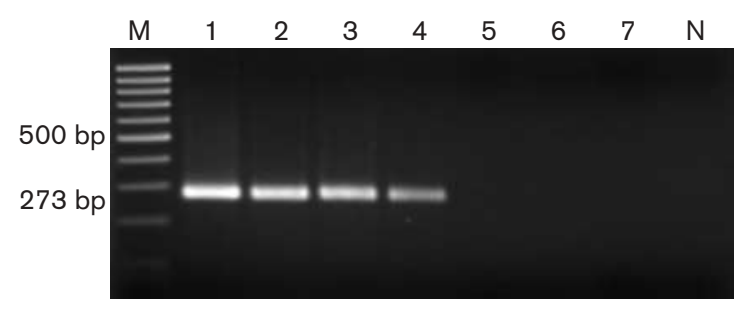

Fig. 4. Agarose electrophoretic gel of LightCycler-amplified DNA from Candida albicans ATCC 14053, showing a single, specific band

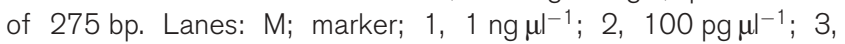

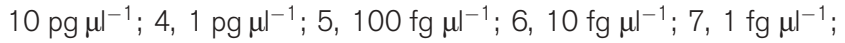
$\mathrm{N}$, negative control (distilled water).

Table 3. $T_{m}$ values of DNA products amplified with speciesspecific primers

\begin{tabular}{|lrc|}
\hline Species tested & $\boldsymbol{n}$ & $\boldsymbol{T}_{\mathrm{m}}($ mean $\pm \mathrm{SD})\left({ }^{\circ} \mathrm{C}\right)$ \\
\hline Candida albicans & 16 & $85 \cdot 71 \pm 0 \cdot 13$ \\
Candida glabrata & 9 & $84 \cdot 02 \pm 0 \cdot 14$ \\
Candida guilliermondii & 8 & $84 \cdot 01 \pm 0 \cdot 28$ \\
Candida krusei & 5 & $90 \cdot 32 \pm 0 \cdot 09$ \\
Candida parapsilosis & 8 & $84 \cdot 43 \pm 0 \cdot 16$ \\
Candida tropicalis & 10 & $84 \cdot 03 \pm 0 \cdot 13$ \\
Cryptococcus neoformans & 2 & $84 \cdot 47 \pm 0 \cdot 29$ \\
\hline
\end{tabular}

\section{ACKNOWLEDGEMENTS}

We would like to express our sincere appreciation to all 22 participating hospitals for providing strains and information related to these strains. They are Chang Gung Memorial Hospital at Linkou, Chang Gung Memorial Hospital at Keelung, Hsin-Chu Hospital, Lo-Tung Poh Ai Hospital, St Mary Hospital, Taipei Municipal Yang-Ming Hospital, Taipei Municipal Zen Ai Hospital, Tao-Yuan General Hospital, Taiwan Adventist Hospital, Koo Foundation Sun Yat-sen cancer center, Tri Service General Hospital, Kuan-Tien General Hospital, Veterans General Hospital-Taichung, Zen Ai General Hospital, Chi Mei Hospital, Kaohsiung Medical College Chung-Ho Memorial Hospital, Kaohsiung Military Hospital, Tainan Municipal Hospital, Veterans General Hospital - Kaohsiung, Buddhist Tzu-Chi General Hospital in HuaLien and Mackay Memorial Hospital Taitung Branch.

\section{REFERENCES}

Bialek, R., Weiss, M., Bekure-Nemariam, K., Najvar, L. K., Alberdi, M. B., Graybill, J. R. \& Reischl, U. (2002). Detection of Cryptococcus neoformans DNA in tissue samples by nested and real-time PCR assays. Clin Diagn Lab Immunol 9, 461-469.

Chen, Y. C., Chang, S. C., Sun, C. C., Yang, L. S., Hsieh, W. C. \& Luh, K. T. (1997). Secular trends in the epidemiology of nosocomial fungal infections at a teaching hospital in Taiwan, 1981 to 1993. Infect Control Hosp Epidemiol 18, 369-375.

Chen, Y. C., Eisner, J. D., Kattar, M. M., Rassoulian-Barrett, S. L., Lafe, K., Bui, U., Limaye, A. P. \& Cookson, B. T. (2001). Polymorphic internal transcribed spacer region 1 DNA sequences identify medically important yeasts. J Clin Microbiol 39, 4042-4051.

Costa, C., Costa, J. M., Desterke, C., Botterel, F., Cordonnier, C. \& Bretagne, S. (2002). Real-time PCR coupled with automated DNA extraction and detection of galactomannan antigen in serum by enzyme-linked immunosorbent assay for diagnosis of invasive aspergillosis. J Clin Microbiol 40, 2224-2227.

Dasbach, E. J., Davies, G. M. \& Teutsch, S. M. (2000). Burden of aspergillosis-related hospitalizations in the United States. Clin Infect Dis 31, 1524-1528.

De Baere, T., Claeys, G., Swinne, D., Verschraegen, G., Muylaert, A., Massonet, C. \& Vaneechoutte, M. (2002). Identification of cultured isolates of clinically important yeast species using fluorescent fragment length analysis of the amplified internally transcribed rRNA spacer 2 region (ITS2). BMC Microbiol 2, 21.

Denning, D. W. (1998). Invasive aspergillosis. Clin Infect Dis 26, 781-803.

Elie, C. M., Lott, T. J., Reiss, E. \& Morrison, C. J. (1998). Rapid identification of Candida species with species-specific DNA probes. J Clin Microbiol 36, 3260-3265.

Ellis, M. E., Al-Abdely, H., Sandridge, A., Greer, W. \& Ventura, W. (2001). Fungal endocarditis: evidence in the world literature, 1965-1995. Clin Infect Dis 32, 50-62.

Espinel-Ingroff, A., Stockman, L., Roberts, G., Pincus, D., Pollack, J. \& Marler, J. (1998). Comparison of RapID yeast plus system with API 20C system for identification of common, new, and emerging yeast pathogens. J Clin Microbiol 36, 883-886.

Fujita, S. I., Senda, Y., Nakaguchi, S. \& Hashimoto, T. (2001). Multiplex PCR using internal transcribed spacer 1 and 2 regions for rapid detection and identification of yeast strains. J Clin Microbiol 39, 3617-3622.

Goodwin, S. D., Fiedler-Kelly, J., Grasela, T. H., Schell, W. A. \& Perfect, J. R. (1992). A nationwide survey of clinical laboratory methodologies for fungal infections. J Med Vet Mycol 30, 153-160. 
Guiver, M., Levi, K. \& Oppenheim, B. A. (2001). Rapid identification of candida species by TaqMan PCR. J Clin Pathol 54, 362-366.

Hazen, K. C. (1995). New and emerging yeast pathogens. Clin Microbiol Rev 8, 462-478.

Henry, T., Iwen, P. C. \& Hinrichs, S. H. (2000). Identification of Aspergillus species using internal transcribed spacer regions 1 and 2. J Clin Microbiol 38, 1510-1515.

Hopfer, R. L., Walden, P., Setterquist, S. \& Highsmith, W. E. (1993). Detection and differentiation of fungi in clinical specimens using polymerase chain reaction (PCR) amplification and restriction enzyme analysis. J Med Vet Mycol 31, 65-75.

Kami, M., Fukui, T., Ogawa, S. \& 14 other authors (2001). Use of realtime PCR on blood samples for diagnosis of invasive aspergillosis. Clin Infect Dis 33, 1504-1512.

Kanbe, T., Horii, T., Arishima, T., Ozeki, M. \& Kikuchi, A. (2002). PCRbased identification of pathogenic Candida species using primer mixes specific to Candida DNA topoisomerase II genes. Yeast 19, 973-989.

Kappe, R., Okeke, C. N., Fauser, C., Maiwald, M. \& Sonntag, H. G. (1998). Molecular probes for the detection of pathogenic fungi in the presence of human tissue. J Med Microbiol 47, 811-820.

Lindsley, M. D., Hurst, S. F., Iqbal, N. J. \& Morrison, C. J. (2001). Rapid identification of dimorphic and yeast-like fungal pathogens using specific DNA probes. J Clin Microbiol 39, 3505-3511.

Lo, H. J., Ho, Y. A. \& Ho, M. (2001). Factors accounting for misidentification of Candida species. J Microbiol Immunol Infect 34, 171-177.

Loeffler, J., Henke, N., Hebart, H., Schmidt, D., Hagmeyer, L., Schumacher, U. \& Einsele, H. (2000). Quantification of fungal DNA by using fluorescence resonance energy transfer and the light cycler system. J Clin Microbiol 38, 586-590.

Luo, G. \& Mitchell, T. G. (2002). Rapid identification of pathogenic fungi directly from cultures by using multiplex PCR. J Clin Microbiol 40, $2860-2865$

Martin, C., Roberts, D., van der Weide, M., Rossau, R., Jannes, G., Smith, T. \& Maher, M. (2000). Development of a PCR-based line probe assay for identification of fungal pathogens. J Clin Microbiol 38, $3735-3742$.

Mitchell, T. G. \& Perfect, J. R. (1995). Cryptococcosis in the era of AIDS - 100 years after the discovery of Cryptococcus neoformans. Clin Microbiol Rev 8, 515-548.

Morrison, C. J. \& Lindsley, M. D. (2002). Serological approaches to the diagnosis of invasive fungal infections. In Fungal Pathogenesis: Principles and Practice, pp. 667-716. Edited by R. Calderone \& R. Cihlar. New York: Marcel Dekker.

Orozco, A. S., Higginbotham, L. M., Hitchcock, C. A., Parkinson, T., Falconer, D., Ibrahim, A. S., Ghannoum, M. A. \& Filler, S. G. (1998). Mechanism of fluconazole resistance in Candida krusei. Antimicrob Agents Chemother 42, 2645-2649.

Pfaller, M. A., Messer, S. A., Boyken, L., Tendolkar, S., Hollis, R. J. \& Diekema, D. J. (2003). Variation in susceptibility of bloodstream isolates of Candida glabrata to fluconazole according to patient age and geographic location. J Clin Microbiol 41, 2176-2179.

Piemonte, P., Conte, G., Flores, C., Barahona, O., Araos, D., Alfaro, J., Fardella, P. \& Thompson, L. (1996). Emergence of fluconazole-resistant infections by Candida krusei and Candida glabrata in neutropenic patients. Rev Med Chil 124, 1149 (in Spanish).

Polak, A. (2003). Antifungal therapy - state of the art at the beginning of the 21st century. Prog Drug Res (Spec. No.), 59-190.

Rex, J. H., Walsh, T. J., Sobel, J. D., Filler, S. G., Pappas, P. G., Dismukes, W. E. \& Edwards, J. E. (2000). Practice guidelines for the treatment of candidiasis. Infectious Diseases Society of America. Clin Infect Dis 30, 662-678.

Spiess, B., Buchheidt, D., Baust, C., Skladny, H., Seifarth, W., Zeilfelder, U., Leib-Mosch, C., Morz, H. \& Hehlmann, R. (2003). Development of a LightCycler PCR assay for detection and quantification of Aspergillus fumigatus DNA in clinical samples from neutropenic patients. J Clin Microbiol 41, 1811-1818.

Stevens, D. A., Kan, V. L., Judson, M. A. \& 7 other authors (2000). Practice guidelines for diseases caused by Aspergillus. Infectious Diseases Society of America. Clin Infect Dis 30, 696-709.

Turenne, C. Y., Sanche, S. E., Hoban, D. J., Karlowsky, J. A. \& Kabani, A. M. (1999). Rapid identification of fungi by using the ITS2 genetic region and an automated fluorescent capillary electrophoresis system. J Clin Microbiol 37, 1846-1851.

White, P. L., Shetty, A. \& Barnes, R. A. (2003). Detection of seven Candida species using the Light-Cycler system. J Med Microbiol 52, 229-238.

Yamada, Y., Makimura, K., Merhendi, H., Ueda, K., Nishiyama, Y., Yamaguchi, H. \& Osumi, M. (2002). Comparison of different methods for extraction of mitochondrial DNA from human pathogenic yeasts. Jpn J Infect Dis 55, 122-125.

Yeo, S. F. \& Wong, B. (2002). Current status of nonculture methods for diagnosis of invasive fungal infections. Clin Microbiol Rev 15, 465-484. 